\title{
Research on the Flipped Classroom Mode: Take "the Customer Relationship Management" Course for Example
}

\author{
Jun Ke \\ Business College of Yangzhou University, Yangzhou, Jiangsu Province, China \\ ke.jun@foxmail.com
}

Keywords: Customer Relationship Management; Teaching Reform; Flipped Class

\begin{abstract}
Customer relationship management (CRM) is a newly emerging course which combination of practice and theory. It is particularly important to adopt suitable teaching methods to obtain satisfactory teaching results. As a new teaching mode, flipped classroom overturns the traditional teaching process and explores a new path for the reform of the customer relationship management teaching mode. This article starts with the introduction of the teaching of customer relationship management and the connotation and function of turning over the classroom. The article analyzes the problems existing in the teaching practice of customer relationship management in the flipped classroom, explores its root causes and puts forward reasonable countermeasures according to the actual situation.
\end{abstract}

\section{Introduction}

Customer Relationship Management is mainly about customer relationship management activities and their regularity. They are applied science based on comprehensive contents such as economic science, behavioral science, computer application and network communication technology. They are comprehensive and practical, The edge of the characteristics. The teaching goal is to familiarize students with the workflow and common tools of customer relationship management and the ability to use Internet tools and customer relationship management methods for network planning and promotion and online promotion.

As customer relationship management is a new interdisciplinary subject, it is also a subject that integrates theory with practice. It is difficult to teach, teaching is poor, and there is a lack of composite faculty. Practical environment is not practical. Problems such as slow updating of teaching materials, etc. . In response to this, many educators have adopted various teaching methods such as project teaching method, case analysis method and virtual experiment platform to conduct various kinds of practices and partially solve such problems. In recent years, the introduction of flip classroom practice, the advantages of integrating various methods for customer relationship management teaching pointed out a new direction.

Flipped Classroom is known as "Reversing Classroom," students see a video before class, read an article or use their old knowledge to think about a problem, then review what they have learned and ask a question ; Teachers design and develop classroom learning materials for students' questions before class; guide students to discuss and solve problems in class. Due to the overturning of the classroom to re-adjust the time inside and outside the classroom, the decision-making power to transfer learning from teachers to students, give full play to the initiative of students, the interaction of the teaching process to a higher level, taking into account the diversity of teaching and teaching students according to their aptitude After a typical teaching practice represented by Khan Academy, it has made remarkable progress in teaching effect and received wide attention from the education community.

Flipped classroom practice effectively solve the teaching of a series of problems. The pre-class knowledge acquisition process is self-learning by students, which solves the problem of passive learning. Teachers in the class organize students to ask questions, discuss and answer questions according to the instructional design and solve the problem of ability cultivation. After class, the students complete the homework and interact with teachers on the network platform to solve the 
problem of teaching students according to their aptitudes. The essence is to emphasize the students before class, self-learning, classroom intensive explanation, personalized guidance after class.

\section{Problems and Causes}

Through the classroom teaching practice of flipped classroom of customer relationship management in multiple classes, the interactive effect between teachers and students is obviously improved in the teaching process, meanwhile reducing the students 'cognitive load, stimulating students' thinking collisions and finally improving the learning effect. At the same time, flipped classroom also triggered a new teaching problem.

The Workload of Teachers Increases. Due to the need for students to acquire knowledge before class, all the courseware and materials are provided by the teacher to re-create, the workload is huge. However, because courseware can be used repeatedly and part of the content is also available on the Internet, to a certain extent, the work of follow-up teaching has been alleviated. Therefore, teachers are still acceptable. The discussion in class needs to be repeated before the class and the students to communicate. Each class needs to be in each class. It is complicated and repetitive work, consuming a lot of energy from the teachers. Homework and Q \& A after class require a great deal of time for each student, with personalized instruction taking up teachers.

The Difference between Teaching Increases. Traditional customer relationship management courses, students in the classroom to accept a unified knowledge of teachers to explain, due to their ability to understand the differences, the teaching results in line with the normal distribution. The flip classroom mode, active self-discipline of students to better learning and interaction, knowledge of the point of understanding and application of more profound, and passive students as a result of unsupervised supervision, to give up the knowledge of learning, At the same time also wasted classroom discussion time, study effect can not talk about. Because of the students' learning habits is difficult to change in the short term, increasing the difference of teaching effectiveness.

Assessment of the Fair is Difficult to Guarantee. The traditional teaching assessment form using papers, assessment of knowledge-based, easy to implement, a sense of fairness and strong students. Flipping classes mostly report the results of the group, it is difficult to distinguish each student, often individual members arranged, the other members of the ride behavior, the final score by the impact of sub-group is greater than the individual's efforts, the sense of fair and poor students, and ultimately affect the learning enthusiasm.

Teachers and students have not changed their role is the root cause of the problem. The role of teachers in overturning classrooms not only did not dilute, and has been strengthened. Although the learning process of the course knowledge point is transferred from the class to the class, how to design the courseware to achieve the learning goal requires the careful consideration of the teacher, how to analyze the situation during the class through questioning, discussion and completion of the homework through the students And grasp the learning effect of students, how to carry out the knowledge leaks and deficiencies in the students' individualization problems after class are different from the traditional teaching mode, the teacher from active to passive, from dominant to guide, which is its Professional qualities have higher requirements. For students, after many years of passive learning mode of training, the general lack of active learning ability, how to learn in class, class discussions, class questions in the process of stimulating enthusiasm for learning, from the theoretical knowledge of simple learning It becomes equally difficult to accomplish this transformation in a short period of time by improving the learning ability of problem solving through the application of theoretical knowledge.

\section{Recommendations}

Unified Development of Curriculum Platform, Saving Teachers' Energy. The knowledge of the course of systematic analysis, unified development. The production of courseware content, knowledge of pre-class point assessment, after-school communication mode, can develop software systems, the answer can be automatically judged and explained by the software, the teacher's energy 
concentration in the class exchange preparation. Knowledge points modular, personalized customization at the same time, will help teachers choose.

Key Chapters to Flip, Improve Learning Efficiency. Flip class need to traditional classroom new design, according to the teaching needs of the trade-offs, which chapter is suitable for pre-class study, which chapter is suitable for classroom explanation, according to the teaching plan for the overall arrangement, not all the contents of the mechanical arrangement to the pre-class study At the same time, pay attention to controlling the time and scope of the class discussion. For example, for the customer relationship management marketing theory chapter, the traditional classroom teaching, easier for students to understand

The use of Process Assessment, Dynamic Grouping, Enhance the Sense of Fairness. For individual pre-class learning process is difficult to assess, and the effect of large differences in the situation, the use of video sign, verification code verification, synchronization and other methods to solve the process of technical assessment problems. During the discussion in class, the discussion group was dynamically adjusted to provide a quantitative basis for the fairness of the students' final grades.

Change the Teaching Management System, to Stimulate the Enthusiasm of Teachers and Students. The original teaching regulations, to adapt to the passive learning mode, the active learning mode teachers and students' efforts without consideration, to a certain extent, affected the initiative of teachers and students. In particular, the use of flip classroom model, teachers and students often assume a certain risk of failure, but also the need for institutional incentives.

\section{Conclusion}

Flipped classroom education practice reflects the direction of the future development of customer relationship management teaching, teaching process from passive to active teaching object from the whole to the individual, have demonstrated great superiority. Even in the current teaching reform of customer relationship management, the overturning classroom is not yet fully equipped with comprehensive implementation conditions. As long as appropriate measures are taken according to local conditions and targeted solutions to the problems in the implementation process will obviously bring about significant improvements in teaching effectiveness.

\section{Acknowledgement}

This research was financially supported by the Jiangsu Province Graduate Education Teaching Reform Project (JGLX-092)

\section{References}

[1] Liu, L. (2009). On Problems of College English Phonetic Teaching for English Majors and Suggestions. Journal of Xi' an Polytechnic University, 23, 147-150.

[2] Dong-jie wang, Dai Weifen. American classroom "reverse" and its use in China [J]. The education theory and practice, 2014, (5): 42 to 45.

[3] Luo Zubing Wen Xiaochuan. Learn the meaning of independence and its implementation [J]. Journal of global education prospects, 2013, (3): 35.

[4] Qi-liang zhang, Wang Aichun. Based on a new type of hybrid "flip" classroom teaching model research [J]. Journal of modern education technology, 2014, (4): 27-32.

[5] Wikipedia. Flipped Classroom: https://en.wikipedia.org/wiki/Flipped_classroom 